\title{
Correction to: Hydroflux-assisted densification: applying flux crystal growth techniques to cold sintering
}

Sarah Lowum ${ }^{1, *}$ (D) Richard Floyd ${ }^{1}$ (D), and Jon-Paul Maria ${ }^{1}$ (D)

${ }^{1}$ Department of Materials Science and Engineering, The Pennsylvania State University, 215 Steidle Building, University Park, PA 16802, USA

Published online:

1 July 2020

(C) Springer Science+Business Media, LLC, part of Springer

Nature 2020

Correction to: J Mater Sci (2020)

https://doi.org/10.1007/s10853-020-04926-7

Due to a production error Fig. 5 in the original article was incomplete. The corrected Fig. 5 is reproduced below.

The original article can be found online at https:/ /doi.org/10.1007/s10853-020-04926-7.

Address correspondence to E-mail: sm192@psu.edu 


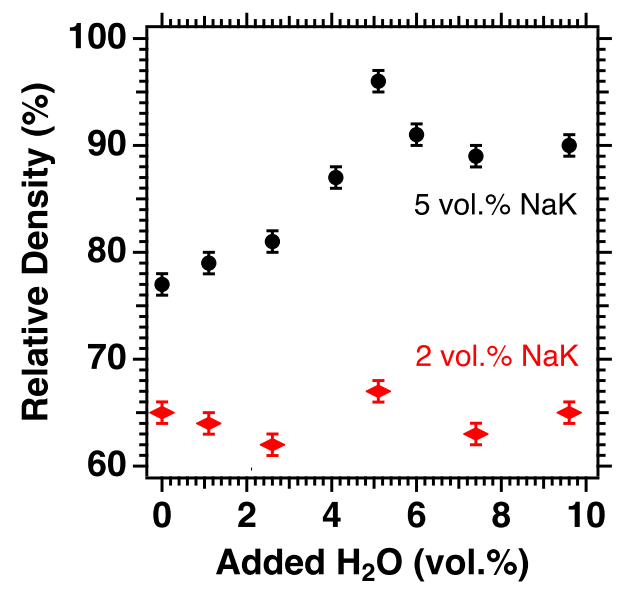

Figure 5 Relative density as a function of volume fraction of added $\mathrm{H}_{2} \mathrm{O}$ for $\mathrm{ZnO}$ samples prepared in the glovebox and coldsintered with 2 and $5 \mathrm{vol} \% \mathrm{NaK}$ at $90 \mathrm{MPa}$ and $200{ }^{\circ} \mathrm{C}$ for $30 \mathrm{~min}$.
Publisher's Note Springer Nature remains neutral with regard to jurisdictional claims in published maps and institutional affiliations. 